\title{
Large Shareholder's Heterogeneity and Loss Reversal of Listed Companies-Evidences Based on Loss Listed Companies in China from 2005 to 2008
}

\author{
Yong $\mathrm{Du}^{1} \&$ Ziqi Meng ${ }^{1} \&$ Yongyan $\mathrm{Zuo}^{2} \& \mathrm{Xing}_{\mathrm{Liu}}{ }^{2}$ \\ ${ }^{1}$ School of Economics and Management, Southwest University, China \\ ${ }^{2}$ School of Economics and Business Management, Chongqing University, China \\ Correspondence: Yong Du, School of Economics and Management, the Southwest University, Beibei District, \\ Chongqing, China. E-mail: dy772012@126.com
}

Received: October 23, 2013

Accepted: January 8, 2014 Online Published: January 20, 2014

doi:10.5539/ijbm.v9n2p135

URL: http://dx.doi.org/10.5539/ijbm.v9n2p135

\begin{abstract}
This paper studies the effect of the heterogeneity of major shareholders of listed companies in China on the loss reversibility after they occur loss. The empirical results show that in the sample of all the losses listed companies, the extent of loss reversal occurred of non-controlling shareholders of listed companies after loss was significantly higher than the losses listed companies of controlling shareholders, that have dispersed ownership and validity checks and balances to shareholders of listed companies to make proactive in losses after losses, but even larger losses reversed, the losses of state-owned controlling shareholders of listed companies and the loss of other listed companies, the largest shareholder of the loss of state property, the largest shareholder of listed companies and the loss of other property companies listed on the extent of the loss is not significantly reversed.
\end{abstract}

Keywords: large shareholder heterogeneity, loss of reversibility, loss of preference, state-controlled, interests seized

\section{Introduction}

In recent years, as the subprime mortgage crisis, the earthquake disaster and such events happen frequently, many enterprises (even public companies ) are difficult to maintain sustained profitable status, not to mention keep sustained growth trend. In fact, due to the impact of these adverse events, most enterprises will fall into financial difficulties, which threatens seriously their survival and development and affects the interests of all parties concerned. Thus, how to save a company from these financial troubles? How to lessen their losses and to make them make profit as soon as possible? The study of such issues as the current company management and stakeholders parties turns to be a more meaningful topic, and this makes the study of changing loss other than sustained surplus appear more urgent and important. However, so far, few scholars both at home and abroad has researched such issues. According to the author's review of related literature at home and abroad, there is no domestic scholars dedicated to study the problems of the company's losses, and almost all foreign scholars remain in the judgment of whether or not the status of loss can be changed, which does not involve a deep study of the authenticity of the company's losses and the reverse degree of the losses and so on. Based on this, the paper probers into the loss reversibility of the public companies. In our country, it is a common phenomenon for the large shareholders to control the public companies. Then, the influence of different major shareholders on the public companies is the same in terms of the loss reversibility? If different, what is the difference and reason? With these questions, this paper mainly analyzes the influence of the heterogeneity of large shareholders on the loss reversibility of the losses of the public companies.

In the context of the current literature we deal with, almost all the research about the properties of the shareholders is based on the classification of controlling shareholder or the largest shareholder, and most of this kind of study is to investigate the relationship or value between different categories of controlling shareholders and the corporate's performance (Shleifer \& Vishny, 1997; Du Ying, Liu Liguo, 2002; Durnev \& Kim, 2005; Xu Liping, Xinyu, \& Chen Gongmeng, 2006, etc.). It is hard to find out the studies of the relationship between the nature of shareholders and the loss reversibility of the companies. With respect to its reason, it may be the less proportion of the public companies in loss among the public companies, which is not typical and easy to be 
ignored by the researchers. In fact, a lot of empirical research literature simply deletes the ST, PT, or the companies with negative net profit when selecting samples. However, in recent years, with the growth of unexpected incidents, the competition and other factors, it turns more and more common for the public companies to suffer loss, which makes the study of the loss reversibility necessary and urgent. This paper attempts to study the relationship between the large shareholder's heterogeneity and the loss reversibility. Theoretically, the paper makes up the shortage of the loss reversibility in the study the sustained surplus, perfecting and enriching the surplus management theories. Practically, the paper reveals the prime cause of the loss of the public companies and the key factors that lead to sustained losses, and find out the impact of these factors on the mechanism of loss reversibility. This is advantageous to the company to timely adjust the management structure, to enhance the early warning capability of financial crisis and the ability to resist the financial risk, and to provide new inspiration for investors to make scientific investment and to further improve the system of stock delisting of our public companies.

Considering the proportion increase of the loss incurred in recent years of the listed companies in China, and the scope of loss larger than before, to make the listed companies out of loss as soon as possible, and to keep the listing qualifications and sustainable development have become an increasingly concerned and important problem for many companies. The paper will focus its study on the influence degree of the heterogeneity of different shareholders of the listed companies on the loss reversibility, analyzing mainly from the major shareholders' drive mechanism and their influence on the loss reversibility. In view of the previous scholars' focus on the study of the listed companies in terms of whether they could reverser the loss or not in the future. (Joos \& Plesko, 2005; Jiang \& Stark, 2006; Kaisis, 2008), and their ignorance of the authenticity and degree of loss reversibility, and their ignorance of the difference as for the large shareholders' appetite of loss, the turnround motivation, the supporting degree, as well as the choice of turnround ways, the paper first takes into account the heterogeneity of large shareholders of the listed companies, and makes a good classification of the major shareholders, and then analyzes the heterogeneity between large shareholders from the appetite of loss, the turnround motivation, the supporting degree, as well as their influence on the loss reversibility of the listed companies. On this basis, the paper puts forward relevant assumptions, and finally summarizes and analyzes the implications and limitations of the policy, combined with the empirical data of the listed companies from 2005 to 2008 and the empirical examination of the influence mechanism.

\section{Theoretical Analysis and Hypothesis}

Classic ownership balance theory holds that the moderate concentration of equity and the ownership structure with certain characteristics of ownership balance can not only have positive incentive effect on large shareholders, solving the problem of equity highly fragmented, but also suppress to a certain the big shareholders' infringe of the interests of small and medium-sized shareholders (such as grab or empty), which is beneficial to promoting the company's operating performance and market value. Therefore, equity checks and balances is a kind of effective governance mechanism (Shleifer \& Vishny, 1986; La Porta et al., 1999; Bennedsen et al., 2000, 2003; Maury \& Pajuste, 2005; Boubakri, 2009). However, the previous scholars based their study on the sample data of or the mixed sample data of profit and loss, and got relevant conclusion. But to the listed companies in loss (here called independent data of loss sample), it needs further analysis and validation of whether or not the ownership restriction validity can normally play its governance role. When the listed companies suffer losses, the big shareholder's heterogeneity is mainly manifested in their preference degree of loss, turnround motivation and supporting degree, etc. The heterogeneity can not only affect the possibility of loss reversibility, but also the degree of loss reversibility in the future. The following content will be specific analysis of the mechanism of large shareholder's heterogeneity on the loss reversibility (Note 1), and on this basis, the relevant assumptions will be put forward.

\subsection{Major shareholders' Property to the Loss Reversibility of the Listed Companies}

The difference of big shareholders' properties is mainly expressed by whether the listed companies have the power of control. The paper, on this basis, divides the major shareholders of the listed companies in loss into two categories, controlling shareholders and non-controlling large shareholders, and through the analysis of the two types of shareholders in terms of the appetite of loss, the turnround motivation and the supporting degree, the paper probes into their influence on the loss reversibility of the listed companies.

Many scholar's research shows that most of the listed companies have the problem of double agency, namely the conflict between the company owners (shareholders) and the management, and the controlling shareholders' encroach of the interests of minority shareholders (Shleifer \& Vishny, 1986; La Porta et al., 1999; Bai Chongen, 2005, etc.). If companies keep growing, controlling shareholders may gain control of the sharing of benefits, 
which makes them have an incentive to supervise the company's managers, reduce agency cost, increase the value of the company, and at the same time, the medium and small shareholders can profit sharing by free-rider (Laeven \& Levine, 2007). However, when the companies decline in performance, especially faced with loss, the controlling shareholders may use their control to avoid their loss, or through the affiliated party transactions transfer the loss they should bear. But non-controlling big shareholders are often powerless, their stock prices will be affected by the negative impact of the losses and fall, and if the loss continues, the wealth of the shareholder will become nothing. Therefore, in this sense, the holding shareholders more disgust the loss than the controlling shareholders, the appetite difference of loss will make the shareholders more strongly reverse the loss than the controlling shareholders. In addition, the relevant domestic research literature of surplus management suggests that if the companies are hopeless to reverse the loss, the controlling shareholders may support the administration through the manipulation of the accrued items (Liu Jianqiao, 1999), the use of asset impairment (Zhao Chunguang, 2006) such as backward means of earnings management, make the listed companies "take a shower", to prepare for next year's profit, and the enterprises with more serious loss will often "big bath" in the fourth quarter of the year. (Zhang Xin, 2008). It shows that the turnround motivation and ability of the controlling shareholders depend on the seriousness of the loss. When the listed companies are hopeless to get the turnround within a year, the controlling shareholder for reasons of long-term interests, may echo or even support management authorities to temporarily accept losses (even huge losses), which leads to their lack of turnround motivation and low turnround support. But the non-controlling large shareholders are more concerned about their short-term interests, and at any time they will be more active to reverse the loss, and show a strong turnround incentives and higher turnround support degree, which makes the listed companies with no controlling shareholders have more degree to reverse the loss than those with controlling shareholders. Thus, this paper puts forward the following assumptions:

Hypothesis 1: The listed companies with no controlling shareholders are stronger to reverse the loss than those with controlling shareholders.

\subsection{Influence of the Controlling Shareholders' Nature on the Loss Reversibility of the Listed Companies}

The difference in the nature of the controlling shareholders are characterized by that the controlling shareholders are state-owned shareholder identity or other shareholder identity (including the shareholders of private sector and private property rights). By analyzing the state-owned shareholders and other stakeholders in terms of their loss appetite, reversibility motivation and supporting degree, we explore their influence on the loss reversibility of the listed companies.

In our country, although the state-owned shareholders' share-holding of the listed companies is nominally controlled by the state, but as a result of the phantom of state-owned shareholders, its actual control often in the hands of the relevant government departments, the cash flow rights of the state-owned controlling shareholders of the listed companies are highly fragmented in the nation people's hands (Shirley \& Walsh, 2000; Xu Liping etc., 2006), which makes the government departments of the listed companies have no real control of the cash flow, and which separates the state-owned controlling shareholders from the cash flow rights. For the loss of the listed companies, this separation will lead to two effects: one is the deepening of the losses, because the state-owned controlling shareholders care for their own interests and infringe the small and medium shareholders' interests, their selfish behavior making worse the situation of the listed companies. This reflects the loss appetite of the state-owned controlling shareholders; Secondly, the loss is lessened or reversed, because, on the one hand, the separation between company management and control of cash flow right can reduce the government's interference, improving the company performance. (Shleifer \& Vishny, 1993; Shleifer, 1998; Hellman et., 2000); on the other hand because the separation helps to form the internal financing market, effectively alleviate the pressure of the external financing, and reduce the cost of financing (Williamson, 1985; Stein, 1985), which reflects the state-owned controlling shareholders' aversion to loss. From the point of these two effects, the loss appetite of state-owned controlling shareholders is not final, which depends on these two kinds of effect. By contrast, other kinds of controlling shareholders have relatively unified rights between share controlling and cash flow rights, and their own wealth is often closely related to their control of the competence of the listed companies. Therefore, they want to control the performance of the listed companies. In this sense, the other kinds of the controlling shareholders more disgust the loss than the state-owned shareholders. In addition, due to the separation of control and cash flow rights for the state-owned controlling shareholders, their motive of loss reversibility is obviously weaker than that of the other kinds of controlling shareholders. From the supporting degree, the actual controllers of state-owned controlling shareholders, maximizing the interests of their own department, they may ignore the loss of the listed companies, even want to make situation worse by transferring price, making the listed company debt guarantees, and tunneling the listed companies bu means of 
taking up public funds and some other improper ways. Making the overall situation of the listed companies worse. Contrarily, the other controlling shareholders are more strongly linked to the performance of the listed companies, and they will prop the listed companies by selecting related transactions and asset replacement, although they may do this for their future interest to tunnel the companies (Riyanto \& Toolsema, 2003; Tong Yan, Cheng Xiaoke, 2007; Jian \& Wong, 2007). This temporary action may reverse the loss immediately, and may even make the companies make profit. From this perspective, the other controlling shareholders are more supportive to the listed companies than the state-owned controlling shareholders. Thus, the paper puts forward the following assumptions:

Hypothesis 2: To the listed companies with controlling shareholders, the ones with other kinds of shareholders are stronger to reverse the loss than those with state-owned shareholders.

\subsection{The Influence of the Nature of the Largest Shareholder on the Loss Reversibility of the Listed Companies}

Similarly, for the listed companies without controlling shareholders, the nature of the largest shareholder is expressed by that it is state-owned shareholder identity or other shareholder identity, which is also analyzed through the loss appetite, reversibility motivation and supporting degree of the listed companies.

In the listed companies without the controlling shareholders, the first big shareholder neither has the right to control the shareholders' committee, nor to control the board. Lin Jianxiu's (2007) research has shown that for the first big shareholders who do not have the control of the shareholders' committee and board, and when in the face of the same external governance and legal protection of investors, and different companies with same efficiency, the first big state-owned shareholders, therefore, are not obviously different from other listed companies as for the business performance. On this basis, the paper has reason to believe that, when the listed companies suffer loss, the above mode can let all the shareholders of listed companies have strong equity and balance validity, which makes it difficult for any shareholders, including the first big shareholder, to use their own identity for private gain. Therefore, whether it is the state-owned first largest shareholders, or other largest shareholders, it remains the same as for the loss, loss aversion or loss preference. In fact, it means putting the choice of loss preference to the hands of the management authorities of the listed companies, which makes them similar in the preference degree of loss. In addition, for the listed companies without controlling shareholders, due to the highly fragmented shareholding, counterbalance validity between individual shareholders is very high, which makes no conflicts between large shareholders and minority shareholders. But, because there is no controlling shareholders in the internal companies, there will appear a serious agency problem between management and shareholders. At this moment, either the state-owned first largest shareholders, or other big shareholders are only all ears to the will of the management authorities. When the listed companies suffer losses, the management authorities, for reasons to preserve their status and reputation, may try to reverse the loss through a positive earning management, or through a negative earning management. At this time, the state-owned first largest shareholder and the other largest shareholders, who are obedient to the management authorities, either possess strong reversibility motivation, high degree of support, or are in a lack of reversibility motivation and low degree of support, namely these two kinds of largest shareholders are not obviously different in the reversibility motivation and supporting degree. Thus, the paper puts forward the following assumptions:

Hypothesis 3: To the listed companies without controlling shareholders, the largest state-owned shareholder is not obviously different from the other kinds of largest shareholders in terms of the loss reversibility.

\section{Research Design}

\subsection{The Selection of Research Samples}

On April 29, 2005, China Securities Regulatory Commission released the Notice on the Pilot Reform of the Shareholder Structure of Listed Companies, which officially launched the reform of the Shareholder Structure. On September 4, 2005, the commission released the Regulation on the Reform of the Shareholder Structure of Listed Companies, which signified that the reform entered an active, reliable and comprehensive new stage. Considering the great influence of these policies on profitless stock in that year and the subsequent years, the listed companies that underwent loss from 2005 to 2008 will be selected as the whole research sample, but practically the calculation of the variables will cover the data of loss listed companies from 2005 to 2009. The concrete selecting process is as shown in Table 1. 
Table 1. The Selecting Process (the sample period: 2005-2008)

\begin{tabular}{|c|c|c|c|c|c|}
\hline Observation Years & 2005 & 2006 & 2007 & 2008 & total \\
\hline Annual Observed Value of Loss Listed Companies & 209 & 221 & 157 & 298 & 885 \\
\hline \multicolumn{6}{|l|}{ Removal } \\
\hline $\begin{array}{l}\text { Loss Listed Companies of Foreign Investment } \\
\text { Controlling Shareholders }\end{array}$ & 26 & 26 & 19 & 23 & 94 \\
\hline Loss Listed Companies of Financial Insurance & 3 & 1 & 1 & 3 & 8 \\
\hline Loss Listed Companies with data missing & 11 & 14 & 38 & 4 & 67 \\
\hline Loss Listed Companies with data exception & 9 & 7 & 24 & 6 & 46 \\
\hline Final Annual Sample Size & 160 & 173 & 75 & 262 & 670 \\
\hline \multicolumn{6}{|l|}{ Including } \\
\hline Sample Group with Controlling Shareholders & 80 & 69 & 29 & 125 & 303 \\
\hline $\begin{array}{l}\text { Sample Group with State-owned Controlling } \\
\text { Shareholders }\end{array}$ & 63 & 54 & 21 & 89 & 227 \\
\hline $\begin{array}{l}\text { Sample Group with Non-state-owned Controlling } \\
\text { Shareholders }\end{array}$ & 17 & 15 & 8 & 36 & 76 \\
\hline Sample Group with Non-controlling Shareholders & 80 & 104 & 46 & 137 & 367 \\
\hline Sample Group with State-owned First Shareholders & 27 & 38 & 19 & 52 & 136 \\
\hline $\begin{array}{l}\text { Sample Group with Non-state-owned First } \\
\text { Shareholders }\end{array}$ & 53 & 66 & 27 & 85 & 231 \\
\hline
\end{tabular}

\subsection{The Design of Explained Variables}

Given to the particularity of China's capital market, the superiority of quarterly profit forecasting methods mentioned by Xi Zhang (2008) and Kevin (2010), and more distinct loss reversal in the first quarter that most companies attempt to achieve after loss occurred, the balance (namely, JROA12 $=\mathrm{JROA}_{\mathrm{t}+1}-\mathrm{ROAA}_{\mathrm{t}}$ ) between the first quarterly profit after their loss (namely, net profit ratio, $\mathrm{JROA}_{t+1}$ ) and the fourth quarterly profit of the year when loss occurred (namely, $\mathrm{ROAA}_{t}$ ), after the asset standardization, will be used to show the degree of loss reversibility. The bigger the value is, the more loss reversibility that the listed company has achieved. Moreover, cash flow can reflect the real loss status of the listed company, and many scholars have found that the more flow cash there is, the more loss reversibility will appear. Therefore, Net Cash Flow from Operating per share of the year (COPS) and Net Cash Flow of the year (CFPS) will be also adopted as instrumental variables to show the degree of loss reversibility. Besides, in view of the information and promptness quarterly cash flow contains as well as the removal of possible deficiencies in adopting accrual return on assets to measure the degree of loss reversibility, the balance (namely, JCFP12 $=\mathrm{JCFP}_{\mathrm{t}+1^{-}} \mathrm{CFPS}_{\mathrm{t}}$ ) between the Net Cash Flow per share in the first quarter after their loss (namely, JCFP ${ }_{t+1}$ ) and that in the fourth quarter of the year when loss occurred (.e. CFPS $\mathrm{t}$ ), and the balance (namely, JCOP12 $=\mathrm{JCOP}_{\mathrm{t}+1^{-}} \mathrm{COPS}_{\mathrm{t}}$ ) between the Net Cash Flow from Operating per share in the first quarter (namely,, JCOP ${ }_{t+1}$ ) after loss and that in the fourth quarter of the year when loss occurred (namely, COPS ${ }_{\mathrm{t}}$ ) will be used to show the authenticity of loss reversal.

\subsection{The Design of Explaining Variables}

For reflecting large shareholders' heterogeneity of various loss listed companies, the explaining variables are set as follows:

YNKG signifies the existence of controlling shareholders, which is judged by shareholding ratio equal or exceed 30\% according to La Porta et al (1999), Gang Wu, Dan Liu (2008). If there existes such a large shareholder, the value of YNKG is 1 ; if not, the value is 0 .

CQXZ signifies whether the nature of property right of the large shareholder of loss listed companies is state-owned or non- state-owned. If there exists a state-owned controlling shareholder, the value of CQXZ is 1 ; if not, the value is 0 . Here we judge in accordance with whether the first largest shareholder is state-owned or non- state-owned. In the loss listed companies with non-controlling shareholder, if the controlling shareholder is state-owned, the value of CQXZ is 1 ; if not, the value is 0 . Here we judge in accordance with whether the first largest shareholder is state-owned or non- state-owned.

\subsection{The Design of Control Variables}

Considering that, apart of the nature of the largest shareholder, other variables also exerts an influence on loss reversibility of a listed company, some primary control variables are set as follows: 
1) The influence of the first or non-first loss occurrence on loss reversibility. As loss durative will directly determine a company's subsequent performance, the loss history of each company will affect the possibility of its later loss reversal to a large extent. If annual loss occurs in a loss listed company for the first time, the probability of its loss reversal is supposed to be higher than that in those companies which have undergone loss more than once. According to the empirical study by Joos and Plesko (2005), loss frequency and degree of a listed company may influence the probability of loss reversal in the following year. They hold the view that if loss occurs to the listed company for the first time in the current year, compared with the companies that have undergone loss more than once, the probability of loss reversal is bigger. Therefore, we hold the opinion that when loss occurs to a listed company for the first time in the current year, in the following year, compared with the companies which have undergone loss more than once, loss reversibility is bigger. Here, SHCK signifies the first loss of listed companies. If loss occurs to a listed company in the current year, the value of SHCK is 1 ; if not, the value is 0 . It is expected that the first loss of a listed company will exert a positive influence on its loss reversibility.

2) The influence of company scale on loss reversibility. Many scholars have realized that the size of a company has influence on the probability and time of its loss reversal. Satin (1992) thinks that large-scale loss listed companies will more easily get over from financial distress than small-scale ones and the possibility of their survival is bigger. Hayn's study (1995) shows that the loss frequency of large-scale companies is much lower than that of small-scale ones, so the probability of loss reversal is bigger for large-scale companies. Klein and Marquardt (2005) examined the cause of accounting loss and non-accounting loss, covering 259719 samples from 1951 to 2001. They find that the smaller diversification degree the small-scale companies are, the more risks they face, and the more loss is found in money flow with deduction of research and development expenditure. Compared with large scale companies, they are more likely to undergo accounting loss at the end of the business cycle. Thus, it is expected that the company scale will have a positive influence on its loss reversibility, which will be measured with SIZE, the Napierian logarithm of the book value of total assets at the end of the year.

3) The influence of company liabilities on loss reversibility. Judging from the company's capital structure, if a company's asset-liability ratio is too high, it shows that its debt paying ability has demonstrated substantive problems, and the probability of loss reversal will become smaller in the subsequent years. The research of Pope and Wang (2004), Joos and Plesko (2005) shows that the heavier the debt burden of a company is, the less loss reversibility will occur. Thus, it is expected that company liabilities will exert a negative effect on its loss reversibility. Here asset-liability ratio (FZQK) is brought in to show the company's liabilities and measure by using total liabilities of the year when loss occurred divided by total assets.

4) The influence of corporate growth on loss reversibility. Judging from the company's development potential, high sales growth rate means a company will have more capital to make profit, which indicates more possibility of its loss reversal. Rayburn (1987) discovers from his empirical study that in many companies, some special factors such as company scale, corporate growth and debt risk will cause the change of their share price. Easton and Zmijewski (1989), Collins and Kothari (1989), through empirical data analysis, also find that loss reversibility of loss listed companies presents a positive interrelated relationship to the corporate growth. Thus, it is expected the corporate growth will have a positive influence on its loss reversibility. Here income growth variable is brought in and operating revenue growth rate (INZJ) is used to measure.

5) The influence of industry attributes on loss reversibility. Scholars, including Sougiannis (1994), Lev and Sougiannis (1996), Lev and Zarowin (1998), state that these technology intensive loss listed companies, such as Electronic and pharmaceutical enterprises, possess more investment value than other labor or capital intensive loss listed companies, and that there exists correlation between their future business performance and their research and development expenditure. Shortridge (2004) examines the value relevance of research and development expenditure in pharmaceutical industry and has found the positive correlation between the company's research and development expenditure and their share price, especially in the companies with high research and development productivity. Franzen (2006) discovers that for research and development intensive loss listed companies, the empirical model of negative earning can improve its explanatory power by $45 \%$, with adjustment coefficient of negative earning and accounting earning by $32 \%$ and $22 \%$ respectively. Here extractive industry (B) is regarded as benchmarks, industry (INDU) is set as dummy variables to control the influence of differences among industries on loss reversibility.

6) The influence of company's annual status on loss reversibility. Given to each annual business cycle and different status of industry development, the degree of loss reversibility will vary in line with the companies' annual environmental deviation. For this reason, the year of the company is also controlled. Here, 2008 is 
regarded as the criterion, and year (YEAR) is set as dummy variable to control the influence of annual differences on loss reversibility.

\subsection{The Design of Regression Model}

A straightforward procedure to study the possible divergence of loss reversibility among listed companies with large shareholder's heterogeneity is to make a direct comparison of their mean value and median in each group and check out whether the deviation is notable in statistics. In this research, the whole samples of loss listed companies are divided into two groups, namely, the group with controlling shareholders, which falls into the sample group with state-owned shareholders and non-state-owned shareholders, and the group with non-controlling shareholders, which falls into the sample group with state-owned first shareholders and non-state-owned first shareholders. In this way, three pairs are matched and their corresponding loss reversibility is contrasted. Nevertheless, this brief comparison does not take into consideration the influence of control variables, which may exert a big impact on a company's loss reversibility. Therefore, the following model will be adopted in regression analysis to remove the effect of control variables.

Multiple Linear Regression Model on Loss Reversibility:

$$
\begin{aligned}
& \text { REVE }=\alpha+\beta_{1} Y N K G+\beta_{2} \text { SHCK }+\beta_{3} \text { SIZE }+\beta_{4} F Z Q K+\beta_{5} I N Z J \\
& +\sum_{i=1}^{3} \beta_{5+i} Y^{Y} A R \quad+\sum_{j=1}^{11} \beta_{8}+j \text { INDU } j+\varepsilon \\
& \text { REVE }=\alpha+\beta_{1} C Q X Z+\beta_{2} S H C K+\beta_{3} \text { SIZE }+\beta_{4} F Z Q K+\beta_{5} I N Z J \\
& +\sum_{i=1}^{3} \beta_{5+i} Y E A R \quad+\sum_{j=1}^{9} \beta_{8+j} I N D U_{j}+\varepsilon \\
& \text { REVE }=\alpha+\beta_{1} C Q X Z+\beta_{2} S H C K+\beta_{3} \text { SIZE }+\beta_{4} F Z Q K+\beta_{5} \text { INZJ } \\
& +\sum_{i=1}^{3} \beta_{S+i} Y E A R, i+\sum_{j=1}^{11} \beta_{8+j} \text { INDU } j+\varepsilon
\end{aligned}
$$

Model (1) is adopted in regression analysis of the whole sample; Model (2) is adopted in regression analysis of loss listed companies with controlling shareholders and Model (3) is adopted in regression analysis of loss listed companies with non-controlling shareholders. Attention: as the annual sample of loss listed companies with controlling shareholders cover 10 industries in all, only 9 dump variables are set in Model (2). Here, REVE is used in each model to signify loss reversal variable, and JROA12 as loss reversal proxy variable.

$$
\begin{aligned}
& \text { REVE }=\alpha+\beta_{1} \text { YNKG }+\beta_{2} \text { SHCK }+\beta_{3} \text { SIZE }+\beta_{4} F Z Q K+\beta_{5} \text { INZJ } \\
& \begin{array}{l}
\text { REVE }=\alpha+\beta_{1} \text { YNKG }+\beta_{2} \text { SHCK }+\beta_{3} \text { SIZE } \\
+\sum_{i=1}^{3} \beta_{5}+i_{\text {YEAR }}+\sum_{j=1}^{11} \beta_{8}+j \text { INDU } j+\varepsilon
\end{array} \\
& \begin{array}{l}
\text { REVE }=\alpha+\beta_{1} C Q X Z+\beta_{2} \text { SHCK }+\beta_{3} \text { SIZE }+\beta_{4} F Z Q K+\beta_{5} I N Z J \\
+\sum_{5}^{3} \beta_{5}+i \text { YEAR } i+\sum_{i} \beta_{8}+j I N D U j+\varepsilon
\end{array} \\
& \begin{array}{l}
R E V E=\alpha+\beta_{1} C Q X Z+\beta_{2} S H C K+\beta_{3} \text { SIZE }+\beta_{4} F Z Q K+\beta_{5} I N Z J \\
+\sum_{i=1}^{3} \beta_{5}+i \text { YEAR } i+\sum_{j=1}^{11} \beta_{8}+j I N D U j_{j}+\varepsilon
\end{array}
\end{aligned}
$$

The above model 1 is used for the regressive analysis of full sample size, model 2 for the regressive analysis of loss-making listed companies with controlling shareholders, and model 3 for the regressive analysis of loss-making listed companies without controlling shareholders. We notice that because the loss-making listed companies with controlling shareholders cover ten industries, only nine dummy variables are set for model 2 . Here REVE in all models stands for loss reversal variables and JROA12 is used to stand for variable substitution of loss reversal.

\section{Empirical analysis}

\subsection{Descriptive Statistics of All Variables}

Table 2 is the results of descriptive statistics of all variables of all models. 
Table 2. Descriptive statistics of all variables (all sample size)

\begin{tabular}{cccccc}
\hline variables & $\mathrm{N}$ & minimum & maximum & mean value & standard deviation \\
\hline JROA12 & 670 & -0.030 & 1.814 & 0.163 & 0.244 \\
JCOP12 & 670 & -2.202 & 4.690 & -0.095 & 0.481 \\
JCFP12 & 670 & -2.602 & 3.881 & 0.104 & 0.508 \\
JCFP & 670 & -1.790 & 1.635 & -0.006 & 0.248 \\
CFPS1 & 670 & -3.789 & 2.419 & 0.046 & 0.434 \\
YNKG & 670 & 0.000 & 1.000 & 0.452 & 0.498 \\
CQXZ & 670 & 0.000 & 1.000 & 0.542 & 0.499 \\
SHCK & 670 & 0.000 & 1.000 & 0.279 & 0.449 \\
SIZE & 670 & 14.108 & 25.827 & 20.806 & 1.310 \\
FZQK & 670 & 0.041 & 20.247 & 1.137 & 1.900 \\
INZJ & 670 & -1.273 & 2.206 & -0.112 & 0.370 \\
\hline
\end{tabular}

Table 2 clearly indicates that as far as loss reversal variables is concerned, the profit rate of asset of the listed companies in the first quarter after their losses is on the increase with the average growth rate of $16.3 \%$. This implies that most listed companies with losses made their efforts to reverse the loss trend after the losses occur so as to make up for their losses as soon as possible. The net cash flow of each share business activities of those companies decrease in the firs quarter after their losses with an average decrease of 0.095 yuan/share, but the net cash flow of each share of those companies decrease in the firs quarter after their losses the an average decrease of 0.104 yuan/share. This indicates that the cash flow of those listed companies with losses mainly comes from financing and investment. The net cash flow of each share of those companies in the first quarter after their losses is negative value, but the net cash flow of each share in the first year is positive value. This indicated that the net cash flow of listed companies is not enough in the short term but enough in the long term. As far as explanatory variables are concerned the mean value of the presence of controlling shareholders and SE shareholders' equity is about 0.5 , indicating that about a half of the sample companies with losses have controlling shareholders and a half of the sample companies with losses have state-owned largest shareholder. That is to say controlling shareholders and state-owned large shareholders are usual phenomenon. The mean value of first losses is 0.279 , indicating that losses have occurred before this losses of most of the sample companies and one third of the companies with witnessed their first loss in that year. The mean debt values of the sample companies imply that the asset-liability ratio is very high and most companies are in very serious situation. The growth rate of operating revenue of the year when the losses occurred is negative values of the sample companies and this implies that the operating revenue decreased of those companies in the losses-occurring year that is to say the growth of the listed companies with losses is bad.

\subsection{The Comparison of the Mean Value and Median of Loss Reversibility Variables of Different Samples}

Table 3 is the mean values and median of loss reversal variables of the loss-making listed companies with shareholders, the loss-making listed companies without shareholders, the loss-making listed companies with state-owned shareholders, the loss-making listed companies with other controlling shareholders, the loss-making listed companies without controlling shareholders and the first largest shareholder being state-owned shareholder and the loss-making listed companies without controlling shareholders and the first largest shareholder being other shareholder. Table 4 is about the mean value of loss reversal variables and median values difference of different groups. 
Table 3. Mean value of loss reversal variables and median values

\begin{tabular}{lllllllllllllll}
\hline category & \multicolumn{3}{c}{ Loss-making listed companies with controlling } \\
shareholders
\end{tabular}

Note: YKGG refers to the loss-making listed companies with controlling shareholders. WKGG refers to the loss-making listed companies without controlling shareholders. GYKG refers to the loss-making listed companies with state-owned controlling shareholder. QTKG refers to the loss-making listed companies with other controlling shareholders. GYDG refers to the loss-making listed companies without controlling shareholders and the first large shareholder being state-owned shareholders. WKGG refers to the loss-making listed companies without controlling shareholders and the first large shareholder being other shareholders.

Table 4. The comparison of the mean value and median of loss reversal variables of different samples

\begin{tabular}{ccccccc}
\hline \multirow{2}{*}{$\begin{array}{c}\text { Loss reversal } \\
\text { variables }\end{array}$} & \multicolumn{2}{c}{ YKGG and WKGG } & \multicolumn{2}{c}{ GYKG and QTKG } & \multicolumn{2}{c}{ GYDG and QTDG } \\
\cline { 2 - 7 } & $\begin{array}{c}\text { Mean value } \\
\text { comparison }\end{array}$ & $\begin{array}{c}\text { Median } \\
\text { comparison }\end{array}$ & $\begin{array}{c}\text { Mean value } \\
\text { comparison }\end{array}$ & $\begin{array}{c}\text { Median } \\
\text { comparison }\end{array}$ & $\begin{array}{c}\text { Mean value } \\
\text { comparison }\end{array}$ & $\begin{array}{c}\text { Median } \\
\text { comparison }\end{array}$ \\
\hline JROA12 & $4.007^{* * *}$ & $3.146^{* * *}$ & $2.725^{* * *}$ & 0.666 & $2.953^{* * *}$ & $3.045^{* * *}$ \\
JCOP12 & $1.755^{*}$ & $2.778^{* * *}$ & -0.198 & 0.337 & 1.638 & $2.084^{* *}$ \\
JCFP12 & -0.377 & 0.010 & $2.214^{* *}$ & $2.419^{* *}$ & 1.228 & 0.561 \\
JCFP & 1.095 & 1.311 & $2.259^{* *}$ & $2.239^{* *}$ & 0.871 & 0.518 \\
CFPS1 & $2.341^{* *}$ & $2.174^{* *}$ & $2.099^{* *}$ & $2.731^{* * *}$ & -1.076 & 0.958 \\
\hline
\end{tabular}

Note: Mean value comparison is about $\mathrm{t}$ statistic of $\mathrm{T}$ test and median comparison is about $\mathrm{t}$ statistic of Mann-Whitney $\mathrm{U}$ test. The signs: ***, ** and * stand for the significance level of $1 \%, 5 \%$ and $10 \%$.

Table 4 indicates that:

1) The loss reversal comparison of the companies with controlling shareholders and those without controlling shareholders. The comparison results indicate, the mean value of return on net worth and the median values of the loss-making listed companies with controlling shareholders in the first quarter are much lower than that of the loss-making listed companies without controlling shareholders on the statistic level of $1 \%$. The mean value and the median values of cash flow of each share business activities of the loss-making listed companies with controlling shareholders in the first quarter are much lower than that of the loss-making listed companies without controlling shareholders on the statistic level of $10 \%$ and $1 \%$. The mean value of the net cash and the median values of the loss-making listed companies with controlling shareholders in the first year are much lower than that of the loss-making listed companies without controlling shareholders on the statistic level of 5\%. The statistics indicate that the net cash flow of each business activity of the loss-making listed companies without controlling shareholders is higher than that of the loss-making listed companies with controlling shareholders and the loss reversal process is much faster than the loss-making listed companies without controlling shareholders after the losses occurred. But this table also implies that there are no evident statistic differences between the loss-making listed companies with controlling shareholders and the loss-making listed companies without controlling shareholders.

2) The loss reversal comparison of the companies with state-owned controlling shareholders and other controlling shareholders. The table indicates that the mean value of return on net worth of the loss-making listed companies with state-owned controlling shareholders in the first quarter are much lower than that of the loss-making listed companies with other controlling shareholders on the statistic level of $1 \%$. The table indicates 
that the median value of return on net worth of the loss-making listed companies with state-owned controlling shareholders in the first quarter is not so evident but still much lower than that of the loss-making listed companies with other controlling shareholders. The mean shift and the median values of cash flow of each share of the loss-making listed companies with state-owned controlling shareholders in the first quarter are much lower than that of the loss-making listed companies without controlling shareholders on the statistic level of 5\%. The mean value and the median values of cash flow of each share of the loss-making listed companies with state-owned controlling shareholders in the first quarter are much lower than that of the loss-making listed companies without controlling shareholders on the statistic level of. The mean value and the median values of cash flow of each share of the loss-making listed companies with state-owned controlling shareholders in the first year are much lower than that of the loss-making listed companies without controlling shareholders on the statistic level of $5 \%$ and $1 \%$. The statistics indicate that the net cash flow of each share of the loss-making listed companies with other controlling shareholders is higher than that of the loss-making listed companies with controlling shareholders and the loss reversal process is much faster than the loss-making listed companies with state-owned controlling shareholders after the losses occurred. But this table also implies that there are no evident statistic differences between the loss-making listed companies with state-owned controlling shareholders and the loss-making listed companies with other controlling shareholders.

3) The loss reversal comparison of the companies whose first large shareholders are state-owned shareholders and whose first large shareholders are other shareholders.

The table indicates that the mean shift of return on net worth of the loss-making listed companies with state-owned controlling shareholders in the first quarter is much lower than that of the loss-making listed companies with other controlling shareholders on the statistic level of $1 \%$. This indicates that the loss reversal of the loss-making listed companies with state-owned controlling shareholders is faster than the loss-making listed companies with other controlling shareholders after losses occur. The mean shift and median also indicate that the median shift of net cash flow of each share business activity in the first quarter is evident on the statistic level of $5 \%$ of the two kind of companies, no evident statistic differences of other variables are found and this tells us that no evident differences can be found in cash flow of these two kinds of companies.

\subsection{Correlation Analysis of all Variables}

Person analysis of other variables expect for year and industry variables

Table 5. Person correlation coefficient matrix

\begin{tabular}{|c|c|c|c|c|c|c|c|}
\hline variables & & JROA12 & YNKG & SHCK & SIZE & FZQK & INZJ \\
\hline \multirow{2}{*}{ JROA12 } & Pearson correlation & 1 & $-0.153 * *$ & $-0.222 * *$ & $-0.411 * *$ & $0.624 * *$ & $-0.261 * *$ \\
\hline & significance(bilateral) & & 0.000 & 0.000 & 0.000 & 0.000 & 0.000 \\
\hline \multirow{2}{*}{ YNKG } & Pearson correlation & $-0.153 * *$ & 1 & $0.170^{* *}$ & $0.245^{* *}$ & $-0.092 *$ & $0.084 *$ \\
\hline & significance(bilateral) & 0.000 & & 0.000 & 0.000 & 0.017 & 0.030 \\
\hline \multirow{2}{*}{ SHCK } & Pearson correlation & $-0.222 * *$ & $0.170^{* *}$ & 1 & $0.334 * *$ & $-0.176^{* *}$ & $0.176^{* *}$ \\
\hline & significance(bilateral) & 0.000 & 0.000 & & 0.000 & 0.000 & 0.000 \\
\hline \multirow{2}{*}{ SIZE } & Pearson correlation & $-0.411 * *$ & $0.245^{* *}$ & $0.334 * *$ & 1 & $-0.437 * *$ & $0.219 * *$ \\
\hline & significance(bilateral) & 0.000 & 0.000 & 0.000 & & 0.000 & 0.000 \\
\hline \multirow{2}{*}{ FZQK } & Pearson correlation & $0.624 * *$ & $-0.092 *$ & $-0.176 * *$ & $-0.437 * *$ & 1 & $-0.195 * *$ \\
\hline & significance(bilateral) & 0.000 & 0.017 & 0.000 & 0.000 & & 0.000 \\
\hline \multirow{2}{*}{ INZJ } & Pearson correlation & $-0.261 * *$ & $0.084^{*}$ & $0.176^{* *}$ & $0.219 * *$ & $-0.195 * *$ & 1 \\
\hline & significance(bilateral) & 0.000 & 0.030 & 0.000 & 0.000 & 0.000 & \\
\hline
\end{tabular}

Note: due to the limited space, this table only provides the correlation analysis of JROA12 and other variables reflecting loss reversal, and the correlation analysis of other variable can also be provided if necessary. **. On .01 level(bilateral)significantly correlated. *. On 0.05 level(bilateral)significantly correlated. 
Table 5 indicates that there exists 1\% negative correlation between loss reversal variable (JROA12), and YNKG, SHCK, SIZE, INZJ, and $1 \%$ positive correlation between loss reversal variable (JROA12) and FZQK. This further indicates that the loss reversal of the companies without controlling shareholders is faster than the companies with controlling shareholders. The loss of the listed companies which have suffered from losses before is larger than those listed companies which experience losses for the first time. The smaller the listed companies are, the greater their reversals are. The loss reversal of the listed companies with poor growth is comparatively great. In the correlation of the explanation variables and controlling variables, though there exists strong correlation between them, the variance inflation factor is less than 2 in the collinearity diagnostics. Therefore this will not influence the following multiple linear regression.

\subsection{Regression Analysis}

SPSS17.0 is used to do multiple linear regression analysis of each models as is shown in table 6 , which indicates that $\mathrm{F}$ value of model regression test of all samples and grouped samples is significant on statistic $1 \%$. This implies that the fitting effects of regression models are good. Because the maximum of variance inflation factor of all test variables and control variables is less than 2 and tolerance is more than 0.5 , no serious multicollinearity exists between all variables. The Durbin-Watson of each model is close to 2, indicating that there exists no 1 sequence correlation of each models.

Table 6. The Regression results of 2005-2008 all samples and grouped samples

\begin{tabular}{|c|c|c|c|c|c|c|c|c|c|c|c|c|}
\hline \multirow{4}{*}{ variables } & \multicolumn{4}{|c|}{ All samples } & \multicolumn{4}{|c|}{ Samples with controlling shareholders } & \multicolumn{4}{|c|}{ Samples without controlling shareholders } \\
\hline & \multicolumn{2}{|c|}{$(01)$} & \multicolumn{2}{|c|}{ (1) } & \multicolumn{2}{|c|}{$(02)$} & \multicolumn{2}{|c|}{ (2) } & \multicolumn{2}{|c|}{$(03)$} & \multicolumn{2}{|c|}{ (3) } \\
\hline & \multirow[b]{2}{*}{ coefficient } & $\mathrm{T}$ & \multirow[b]{2}{*}{ coefficient } & \multirow{2}{*}{$\begin{array}{c}\mathrm{T} \\
\text { value }\end{array}$} & \multirow[b]{2}{*}{ coefficient } & \multirow{2}{*}{$\begin{array}{c}\mathrm{T} \\
\text { value }\end{array}$} & \multirow[b]{2}{*}{ coefficient } & \multirow{2}{*}{$\begin{array}{c}\mathrm{T} \\
\text { value }\end{array}$} & \multirow[b]{2}{*}{ coefficient } & $\mathrm{T}$ & \multirow[b]{2}{*}{ coefficient } & \multirow{2}{*}{$\begin{array}{c}\mathrm{T} \\
\text { value }\end{array}$} \\
\hline & & value & & & & & & & & value & & \\
\hline intercept & $0.562 * * *$ & 4.165 & $0.565 * * *$ & 2.885 & $0.493 * * *$ & 4.336 & $0.439 * * *$ & 3.313 & $0.466^{*}$ & 1.959 & $0.523 *$ & 1.758 \\
\hline YNKG & $-0.027 *$ & -1.816 & $-0.034 * *$ & -2.288 & & & & & & & & \\
\hline CQXZ & & & & & -0.008 & -0.525 & -0.014 & -0.904 & -0.038 & -1.545 & -0.037 & -1.466 \\
\hline SHCK & $-0.032 *$ & -1.868 & $-0.034 * *$ & -1.980 & $-0.027 * *$ & -1.987 & $-0.025^{*}$ & -1.774 & -0.044 & -1.449 & -0.043 & -1.421 \\
\hline SIZE & $-0.022 * * *$ & -3.448 & $-0.022 * * *$ & -3.131 & $-0.019 * * *$ & -3.543 & $-0.017 * * *$ & -2.893 & -0.018 & -1.533 & -0.020 & -1.635 \\
\hline FZQK & $0.069 * * *$ & 16.323 & $0.069^{* * *}$ & 16.203 & $0.046 * * *$ & 11.249 & $0.048 * * *$ & 11.256 & $0.079 * * *$ & 12.001 & $0.078 * * *$ & 11.590 \\
\hline INZJ & $-0.076 * * *$ & -3.818 & $-0.072 * * *$ & -3.585 & $-0.047 * *$ & -2.517 & $-0.051 * * *$ & -2.618 & $-0.091 * * *$ & -2.899 & $-0.083 * * *$ & -2.638 \\
\hline Year & \multicolumn{2}{|c|}{ Without control } & \multicolumn{2}{|c|}{ control } & \multicolumn{2}{|c|}{ Without control } & \multicolumn{2}{|c|}{ control } & \multicolumn{2}{|c|}{ Without control } & \multicolumn{2}{|c|}{ control } \\
\hline industry & \multicolumn{2}{|c|}{ Without control } & \multicolumn{2}{|c|}{ control } & \multicolumn{2}{|c|}{ Without control } & \multicolumn{2}{|c|}{ control } & \multicolumn{2}{|c|}{ Without control } & \multicolumn{2}{|c|}{ control } \\
\hline sample & 670 & & 670 & & 303 & & 303 & & 367 & & 367 & \\
\hline $\mathrm{F}$ & 101.80 & $* * *$ & 28.105 & & 44.615 & & 14.562 & & 57.611 & & 16.737 & \\
\hline Adj R2 & 0.43 & & 0.43 & & 0.41 & & 0.43 & & 0.43 & & 0.45 & \\
\hline Durbin-Watson & 1.96 & & 2.01 & & 1.89 & & 2.03 & & 1.97 & & 2.11 & \\
\hline VIFmax & 1.41 & & 1.61 & & 1.18 & & 1.50 & & 1.55 & & 1.72 & \\
\hline
\end{tabular}

Note: $* * * * *$ and $*$ stand for the significance level of $1 \%, 5 \%$ and $10 \%$. Control in year dummy variables and industry dummy variables mean that they get involved in the regression of the models concerned. "Without control" indicates that they don't get involved in the regression of the models concerned. Due to the limited space, the test results of annual dummy variables and industry dummy variables are not listed, this paper only does the regression analysis of JROA12.

First, the regression results of all samples indicate that:

(1) Explanation variables: for both model 1 of control year and industry variables and model 01 without control year and industry variables, YNKG is in line with expectation and is statistically negative. This further implies that the loss reversal of the loss-making listed companies without controlling shareholders is faster than the companies with controlling shareholders after the losses occur, so hypothesis 1 verified. The possible reasons are as follows: the loss-making listed companies have separated stock rights which result in checks and balances among shareholders, so the companies would work actively to reverse their losses. But for the companies with 
controlling shareholders, because these controlling shareholders have control over the profits, they will make more profits of themselves by earnings management and related party transaction(Barclay \& Holderness, 1989; Bergstrom \& Rydqvist, 1990; Claessens,Djankov and Lang,2000; Bertrand, Mehta and Mullainathan, 2002; Bae,Kang \& Kim, 2002; Li Zengquan, Sun Zheng, Wang Zhiwei, 2004; Liu Feng, He Jiangang, Wei Minghai, 2004; Lui Changjiang, Xiao chengmin, 2006; Gao Lei, Sun Shunlin, 2007), When losses of their companies occur, these shareholders will probably neglect the situation or minimize their losses to decrease their joint liability by investment reduction, divestment, asset transfer etc. This usually makes the situation worse.Therefore although non-controlling shareholders do their best to reduce losses, their efforts are not as effective as they expect so the loss reversal of the companies with controlling shareholders is not as good as those companies without controlling shareholders. But this is in not line with the research by the scholars such as Friedman, Johnson and Mitton (2003), Riyanto and Toolsema (2004), Li Zengquan, Yu Qian, Wang Xiaokun (2005), Zhang Guangrong, Zeng Yong (2006), Ning Yuxin, Ke Dagang (2006), Tong Yan, Chen Xiaoke (2007), Jian and Wong (2007). Friedman, Johnson and Mitton (2003) hold that in the market where the investors are not well legally protected, the controlling shareholders of listed companies have tunneling motives, but when listed companies are in trouble, they still have propping motives. They hold that controlling shareholders will not always empty their own companies, and they support their companies especially when their companies are in financial trouble. The possible reason of the differences lines in the samples chosen. Almost all listed companies in these researches which support their own companies in financial trouble are profit-making companies or the mix of profit-making companies and loss companies (profit-making companies are much more than the loss companies). Controlling shareholders are confident of the future of their own companies, so even if the companies are in temporary financial trouble, they will do their best to support the companies so as to make more profits when the situation is reversed. For loss-making listed companies however, especially the companies which have witnessed continuous losses for years or which have suffered from huge losses, controlling shareholders are not confident, different from the researches by the above scholars. On the contrary, they neglect the situation or reduce their investment.

(2) Control Variables. For both model 1 of control year and industry variables and model 01 without control year and industry variables, SHCK is not in line with expectation and is statistically negative and is significantly negative of $10 \%$ and $5 \%$. This further implies that the losses of the listed companies which undergo first losses are less than the listed companies which have had losses especially continual losses. This is probably due to the regulation of ST and PT and the limitation of delisting system. According to "Suspending and Terminating the Listings of Loss-making Listed Companies Implementing Procedures (Revised) Supplementary Provisions" (implemented on March 18, 2003) by China's Securities Regulatory Commission, ST system will be applied to the listed companies which have undergone losses for 2 continuous years or have one year's losses and the net assets drop less than the par value, or serious illegal activities. If ST companies have other problems such as the losses of three continual years, PT will be applied. If three continuous years' losses do occur and the situation is not reversed, the companies will be unlisted. So for the listed companies which have undergone losses, they will do their best to make profits in order to avoid ST and PT. So their reversal is greater than the companies with their first losses. For model 1 and model 01, the variable SIZE is not in line with expectations and is significantly negative on the level of $1 \%$. This indicates that the smaller the listed companies, the greater the reversal is after the losses and this again is not in line with the researches by Hayn (1995), and Klein and Marquardt (2005). This is probably because the burdens are not so heavy for small loss-making listed companies of China and they are more flexible, once losses occur, it is much easier to reverse the situation in a short term than large companies. For model 1 and model 01, the variable FZQK is not in line with expectations and is significantly positive on the level of . This indicates that the more debts the loss-making companies have, the more possible it is to reverse the situation and this conflicts with the research by Joos and Plesko (2005). It is probably because the asset-liability ratio of the listed companies of China is very high(the asset-liability ratio of all samples in table 4 is $113.7 \%$ )and the assets of most listed companies can even make up for its debts. So the situation makes creditors do their best to help these companies to get out of troubles and the loss-making listed companies with heavy debts are much more possible to reverse loss-making situation. For model 1 and model 01 , the variable INZJ is not in line with expectations and is significantly positive on the level of. This indicates that the loss reversal of the companies with bad growth is greater than the companies with good growth and this is different from the researches by Easton and Zmijewski (1989) and Collins, Kothari (1989). This is probably because the growth rate of operating revenue of the loss-making listed companies are universally negative (the growth rate of operating revenue of all samples in table 4 is $-11.2 \%$ ), that is, the operating revenue of most companies is on the decrease. Therefore, the loss-making listed companies with big decrease of operating revenue will take every possible measure to reverse the situation and the reversal of those companies are faster 
than the companies with small decrease of operating revenue .

Secondly, the regression results of the companies with controlling shareholders indicate:

(1) Explanation variables: for both model 2 of control year and industry variables and model 02 without control year and industry variables, CQXZ is in line with expectation but is not statistically significant. This indicates that though the reversal of the loss-making listed companies with state-owned shareholders is less than that of the companies with other controlling shareholders but the reversal differences are not significant, so hypothesis 2 can not be verified. This is probably because for the companies with both state-owned and other controlling shareholders, when losses occur in their companies, they will act unanimously to protect their companies from losses. Namely they will take financial measures to support those companies with temporary and small losses and wait to make profits when the losses are finally reversed. However, they will minimize their losses by investment reduction, divestment, asset transfer, etc for the listed companies with long-term and serious losses and this will undoubtedly make the situation worse.

(2) Control variables: for both model 2 of control year and industry variables and model 02 without control year and industry variables, the variables SHCK, SIZE, FZQK and INZJ is in line with regression coefficient and statistic significance of all samples.

Last, the regression of the companies with controlling shareholders indicates

(1) Explanation variables: for both model 3 of control year and industry variables and model 03 without control year and industry variables, the variable CQXZ is in line with expectation but is not statistically significant. This implies that though the reversal of the loss-making listed companies with state-owned controlling shareholders is less than that of the loss-making listed companies with other controlling shareholders, the reversal differences are not so evident and this prove hypothesis 3 . This is probably because though the first large shareholder in the companies without controlling shareholders has the largest share proportion, the checks and balance among shareholders are very strong because they don't have control over the listed companies. Therefore the first large shareholder is not able to make key decisions. The nature of the first large shareholders has no significant influence on the loss reversal.

(2) Control variables: for both model 3 of control year and industry variables and model 03 without control year and industry variables, the variables SHCK and SIZE is not in line with expectation but is not statistically significant. The regression is different from that of all samples. This is probably because the shareholders of the loss-making listed companies have similar share proportion, resulting in strong checks and balance among them.

This restriction has weakened some shareholders for their own profits by deliberately increasing or reducing the motivation of market company to reverse the loss, limiting these shareholders' behavior deliberately to increase or decrease effect of that no matter whether the company is first loss or not, no matter whether the company size is big or small, the reversal in the event of a loss, there is no obvious difference of degree. Company's liabilities variables (FZQK) and firm growth (i.e., INZJ) on symbols of regression coefficient and significance level are consistent with the regression of the whole samples.Here it will be no discussion.

\subsection{Test on Stability}

In order to investigate the reliability of the above research results, this article gives portrait directly on whether there is the controlling shareholder of the explanatory variables using the measurement method of the ratio of the first largest shareholder, based on the fact that the higher the ratio of the first largest shareholder is, the greater the possibility of controlling shareholder is. In addition, in this paper, the property nature of the controlling shareholder and the first big shareholders is used to measure by nature proportion of state-owned shares. Its basis is: in both a sample group of the non-controlling shareholders and the sample group of the controlling shareholders, tend to be state-owned shares that the nature of the property of the market company is. As a result, the regressions of above model are shown in table 7 . 
Table 7. The research results on the stability test from the whole samples and the group samples in 2005-2008.

\begin{tabular}{|c|c|c|c|c|c|c|c|c|c|c|c|c|}
\hline \multirow{3}{*}{ variables } & \multicolumn{4}{|c|}{ All samples } & \multicolumn{4}{|c|}{ Samples with controlling shareholders } & \multicolumn{4}{|c|}{ Samples without controlling shareholders } \\
\hline & \multicolumn{2}{|l|}{$(01)$} & \multicolumn{2}{|l|}{ (1) } & \multicolumn{2}{|l|}{$(02)$} & \multicolumn{2}{|l|}{ (2) } & \multicolumn{2}{|l|}{ (03) } & \multicolumn{2}{|l|}{ (3) } \\
\hline & coefficient & $\begin{array}{l}\mathrm{T} \\
\text { value }\end{array}$ & coefficient & $\begin{array}{l}\mathrm{T} \\
\text { value }\end{array}$ & coefficient & $\begin{array}{l}\mathrm{T} \\
\text { value }\end{array}$ & coefficient & $\begin{array}{l}\mathrm{T} \\
\text { value }\end{array}$ & coefficient & $\begin{array}{l}\mathrm{T} \\
\text { value }\end{array}$ & coefficient & $\begin{array}{l}\mathrm{T} \\
\text { value }\end{array}$ \\
\hline intercept & $0.596 * * *$ & 4.450 & $0.615^{* * *}$ & 3.152 & $0.489 * * *$ & 4.317 & $0.437 * * *$ & 3.302 & $0.502^{* *}$ & 2.127 & $0.579 *$ & 1.953 \\
\hline YNKG & -0.033 & -0.649 & -0.071 & -1.357 & & & & & & & & \\
\hline CQXZ & & & & & -0.031 & -1.154 & -0.035 & -1.277 & -0.112 & -1.400 & $-0.141^{*}$ & -1.744 \\
\hline SHCK & $-0.034 * *$ & -1.976 & $-0.035^{* *}$ & -2.037 & $-0.028 * *$ & -2.031 & $-0.026^{*}$ & -1.839 & -0.041 & -1.325 & -0.039 & -1.271 \\
\hline SIZE & $-0.024 * * *$ & -3.730 & $-0.023 * * *$ & -3.360 & $-0.019 * * *$ & -3.471 & $-0.017 * * *$ & -2.864 & $-0.019 *$ & -1.712 & $-0.021^{*}$ & -1.802 \\
\hline FZQK & $0.068^{* * *}$ & 16.250 & $0.069 * * *$ & 16.118 & $0.046^{* * *}$ & 11.223 & $0.048 * * *$ & 11.215 & $0.079 * * *$ & 11.925 & $0.077 * * *$ & 11.497 \\
\hline INZJ & $-0.077 * * *$ & -3.841 & $-0.073 * * *$ & -3.599 & $-0.047 * *$ & -2.525 & $-0.052 * * *$ & -2.699 & $-0.093 * * *$ & -2.954 & $-0.085^{* * *}$ & -2.690 \\
\hline Year & Without control & & control & & Without con & & control & & Without con & & control & \\
\hline industry & Without control & & control & & Without con & & control & & Without con & & control & \\
\hline sample & 670 & & 670 & & 303 & & 303 & & 367 & & 367 & \\
\hline $\mathrm{F}$ & $100.793 * * *$ & & $27.783^{* * *}$ & & $44.985^{* * *}$ & & $14.651^{* * *}$ & & $57.459 * * *$ & & $16.827^{* * *}$ & \\
\hline Adj R2 & 0.427 & & 0.432 & & 0.421 & & 0.435 & & 0.435 & & 0.451 & \\
\hline Durbin-Watson & 1.975 & & 2.028 & & 1.903 & & 2.040 & & 1.977 & & 2.097 & \\
\hline VIFmax & 1.393 & & 1.588 & & 1.193 & & 1.503 & & 1.520 & & 1.690 & \\
\hline
\end{tabular}

Note: $* * * * *, *$, it respectively shows in $1 \%, 5 \%, 10 \%$ of the statistical significant level; Annual virtual variables and industry "control" in the virtual variable represent the process involved in the corresponding model of regression. "non-controlling" stands for that it is not involved in the corresponding model of regression process, due to the limitation of space. This article does not list the results of the annual virtual variables and industry virtual; Limited to this space, here only the loss reversal degree of proxy variable regression analysis was conducted for the (JROA12).

Test results are shown in table 7, in the regression of the whole sample group and the sample group of controlling shareholder. Both annual and industry control variables of the model (model 1 and model 2) or model of the year and industry control variables (i.e., the model 01 and 02 ), explanatory variables (if there is controlling shareholders, YNKG; nature of the controlling shareholder, CQXZ) were shown to be explained variable (YNRE losses reverse or not), a negative correlation relationship between it and the expanded .Despite that there is not obvious in statistical sense, but its trend of the direction and multiple linear regression results are consistent.In the absence of the controlling shareholder of the sample group of regression, the model of the year and industry control variables (3) the interpretation of the regression variables (the first big shareholders nature, CQXZ) coefficient is negative, the same was not significant in statistical sense, but in the year and industry control variables of model (3) the explanatory variables coefficient (CQXZ) to $10 \%$ statistical significant negative abnormal level, which to a certain extent, shows the previous explanation the empirical results of the stability of the variable gives. From various groups of control variable regression results, in addition to the sample group for no controlling shareholder return in the first loss (SHCK) or variable coefficient it did not show statistically significant negative. The other control variables regression coefficient of symbols are the same as the previous results of the multiple linear regression, and on the significance level it is also similar, confirming earlier about the reliability of the control variables of the empirical results. In conclusion, the stability test results further prove the stability and reliability of the empirical study results in this paper.

\subsection{Conclusion and Policy Implication}

In view of the previous scholars' focus on the study of problems of reverse loss of the market company incurred to reverse in the future, they ignored the authenticity and the extent of the reverse loss, did not take into account the different nature of the largest shareholder in the attitude of losses, turnround motivation and support degree and turnround way choice,. This article first considers the loss heterogeneity of large shareholders of market companies, has carried on the more comprehensive to it from various angles and meticulous division, then analyzes the all kinds of big shareholders in appetite loss, turnround motivation and support degree and the turnround way choice differences, as well as the different impact on the market company incurred reversal after the loss, coupled with China's stock market from 2005 to 2008 losses ,taking 670 listed companies as the sample 
data, based on the presence of controlling shareholders and large shareholders state-owned property to group the research (including 303 have a controlling shareholder and 367 without a controlling shareholder groups), through independent inspection it is confirmed that the difference of two types of the samples in the heterogeneity of the major shareholders of market companies will lead to the obvious differences in the extent of the loss incurred to reverse. Empirical study results show that in all the losses of the samples of market companies, the ones without loss of the controlling shareholders are significantly better than controlling shareholders of market companies' loss. It shows dispersion of shareholders that equity checks and balances validity would help the market company to be active, and the extent of loss reversal is bigger; In the group samples with the controlling shareholder and without the controlling shareholder ,the losses between, state-owned controlling shareholders of market companies and other controlling shareholder of market company, the first big shareholders of state-owned property losses and the losses of largest shareholder of other property, there is no obvious difference in irreversible degree of loss. This shows that in relatively concentrated equity there is controlling shareholders of market companies loss, whether state-owned controlling shareholders or other holding shareholders, they are out of "pooling" mutual motivation, unconsciously produce consistent behavior; In relatively decentralized equity without loss of the controlling shareholders of market companies, whether it is the first largest shareholders state-owned, big shareholders and other small and medium-sized shareholders, validity of checks and balances between them are obvious. In addition, in this paper, the study also shows that, whether the company's loss is the first time or not, the company size, the company's debt burden, and the company's growth,all the factors have the significant influence.on the extent of the loss incurred to reverse .

This research of the paper enriches the domestic literature on the loss of especially under the condition of market economy research literature on transformation company equity properties and loss reversal problem. By research on relation between shareholder's heterogeneity and loss of reversal, in theory, it makes up the deficiency for the losses in the research study, to improve and enrich theory of ownership balance and earnings management theory, to further expand the financial early warning management theory and risk control theory, In practice, it can reveal the root of the losses of market companies and the key factors that lead to the losses sustained, finding that the impact of these factors on the market company losses reverse mechanism, can help the company timely adjust the structure of corporate governance, to enhance the financial crisis early warning capability and to resist the ability of the financial risk, make scientific investment decision for investors and government regulators to better understand the loss problem of the market companies, and further improve the system of corporate governance of Chinese market companies and the delisting system provides a new enlightenment. During the period of economic transition in China, the loss of the market company with controlling shareholders or without the controlling shareholder, is to give full play to the small and medium-sized shareholders of large shareholders (or controlling shareholders) supervision and checks and balances, restrains large shareholders or controlling shareholders to use their control of the advantage over the interests of minority shareholders. Market companies in the process of turnround, should recognized the big shareholder's heterogeneity, effective supervision and motivation of state-owned large shareholders in the leading role in the process of turnround and give full play to other big shareholders to prevent loss and reverse the enthusiasm. In addition, based on the empirical results it is found that the market company surplus changes is more apparent after the loss of in the first quarter loss than after the first year, and surplus manipulation behavior of the loss-making market company in generally in the fourth quarter of that year is more serious. This article suggests that standards of ST, PT and eventually delisting standards ,should be established in accordance with the quarter of consecutive losses to the market company according to the changes of the market company's quarterly earnings to make more specific and operability of regulatory rules.

The limitations of this study is: due to the small quantity samples, this article does not further divide the nature of state-owned controlling shareholders, in fact, holding market companies can undertake more detailed division. It can be divided into state-owned enterprises holding market companies and market company of state-owned assets supervision and administration institution holding market companies, And because the two have different appetites, turnround motivation and ability and driving effect on the company's value may also vary, which leads to the fact the possibility of loss reversal also may be different. It also can draw lessons from Xu Liping, XinYu, Chen Gongmeng (2006), classification method of the team from school of management in Sun Yat-sen University (2008), it is the controlling shareholder as to the different enterprise state-owned holding market companies for further divided, which can be divided into the losses of state-owned enterprises directly under the central government, holding market companies and local ones in the same way, because of the state-owned enterprises directly under the central government controlling shareholders, they may have different appetites in loss turnround motivation and the ability and driving effect on the company's value may also vary,which leads 
that possibility of a reversal of the losses of state-owned enterprises directly under the central government holdings of market companies and the local ones will be different, too. Of course, these assumptions only the writer makes are just on the basis of the same type of speculation. The research tries to distinguish, but due to the losses of state-owned enterprises directly under the central government holding market companies sample size is too small (from 2005 to 2008 , such losses every year between the market company less than 10), which cannot satisfy the requirement of the statistical test samples.Only way is to collect more losses samples and then make further empirical test to determine whether the hypothesis or not. In addition, when choosing control variables in this paper, there will be no influence on the rate of loss of reverse economic cycle, such as regional difference variables into the control range. While Xue Shuang's (2010) research thinks the company economic environment (including macro economic cycle, the boom of industry, the country's monetary policy and fiscal policy, etc.) and the certain relevance, which may be a certain effects on the research conclusion of this paper.

In this paper, the loss reversibility mainly refers to the degree of the loss reversal of the loss -making companies after the first year (or) in the first quarter of the year.

Lin Jianxiu (2007) reflects the first big shareholders at the shareholders' level and board level control of the different combination with controlling pattern. Namely whether the first big shareholders at the shareholders' level control and whether at board level control, it is divided into four different kinds of control mode: have the board level and at the same time control of the board level (high equity control), and neither have the board level and nor have the control of the board level (low stock control), have the board level control over, but not have board level control (high stakes low control), not have the board level control ,have control board level (low equity high control). According to four kinds of control mode, here the first big shareholders only refers to the low equity control mode, the other three patterns belong to controlling shareholders.

Zhang Xin (2008) research has shown that China's market companies management at loss in those days will be in the fourth quarter earnings management to avoid losses. On the one hand, if the listed company's turnround is expected, they will choose to increase earnings in the fourth quarter to realize the profit; On the other hand, if the listed company was a hopeless that they will choose to increase in the fourth quarter loss preparing for next year to profit.

Zhang Xin (2008), Kevin (2010) will research the time period by the annual loss of heterogeneity further subdivided into quarters, increase the frequency of the sample observation, so as to be more accurately capture the various losses of the company in each quarter turnround by earnings management of the nature of the situation and losses sustained.

But Zhang Xin's (2008) study focuses only on the loss-making market companies whether the market company has smooth profit or "take a shower" earnings management behavior in the annual loss in the fourth quarter, there is no deep research on the loss-making companies quarterly loss may occur after loss-making companies' reversal behavior and its influencing factors. While Kevin (2010) research considers the loss of the possibility of the company's quarterly reversal, but it focuses on the influence factors of loss only includes the history, dividend payments, sales growth and financial information, such as special project spending without considering the corporate governance, audit opinion, special events expected non financial information, and thus analysis is not comprehensive, and the samples selected are largely different from China's companies. The research conclusion is also unable to apply the stock market in China.

Xue Shuang's research (2010) shows that when the macro economy is booming, but the boom of industry is lower, loss the price of the loss-making company is low. When investors show pessimistic attitude to the industry and the company's future. The possibility of the most expected turnround for the company in the future is greatly reduced. On the contrary, when the macro economy is in recession and the boom of industry is high, investor's confidence in the industry will increase, the stock price is also higher. The loss of the company's value is negatively related to the macroeconomic trends, and the boom of industry. She also found that the proactive fiscal policy and loosen monetary policy can reduce the loss or increasing the probability of turnround, therefore, have a positive impact on loss-making company's share prices.

\section{Acknowledgements}

The authors are grateful for financial support from the Fund of Chian Natural Science (71232004) and the Fund of China Social Science (13CGL050) and the Fund of the Ministry of Education of Humanities and Social Sciences (11YJC630243, 12YJC630010, 13YJC630027). 


\section{References}

Barclay \& Hoderness. (1989). Private Benefits from the Control of Public Corporations. Journal of Financial Economics, 25, 371-395. http://dx.doi.org/10.1016/0304-405X(89)90088-3

Beatty, A. L., Ke, B., \& Petroni, K. R. (2002). Earnings management to avoid earnings declines across publicly and privately held banks. The Accounting Review, 3, 547-570. http://dx.doi.org/10.2308/accr.2002.77.3.547

Bergstrom, C., \& Rydqvist, K. (1990). The Determinants of Corporate Ownership: An Empirical Study on Swedish Data. Journal of Banking and Finance, 14, 237-253. http://dx.doi.org/10.1016/0378-4266(90)90048-7

Bertrand, M., Mehta, P., \& Mullainathan, S. (2002). Ferreting Out Tunneling: An Application to Indian Business Groups. The Quarterly Journal of Economics, 1, 121-148. http://dx.doi.org/10.1162/003355302753399463

Chongen, B. (2005). An empirical study of the governance structure of market companies in China. Economic Research, 2.

Chunguang, Z. (2006). Asset impairment and earnings management. Accounting Research.

Claessens, P. S., \& Djankov, S. (2000). The separation of ownership and control in East Asian corporations. Journal of International Money and Finance, 16, 189-209.

Claessens, S., Djankov, S., \& Lang, L. (2000). The separation of ownership and control in East Asian $\begin{array}{lllll}\text { corporations. Journal of } & \text { Financial }\end{array}$ http://dx.doi.org/10.1016/S0304-405X(00)00067-2

Collins, D. W., \& Kothari, S. P. (2002). An analysis of the inter-temporal and cross-sectional determinants of earnings response coefficients. Journal of Accounting and Economics, 11, 143-181. http://dx.doi.org/10.1016/S0304-405X(00)00067-2

Dan, S. D., Steven, K., Rick, L., \& Eric, W. (2009). The Information Content of Tax Expense for Firms Reporting Losses. Working paper.

Darrough, M., \& Ye, J. (2007). Valuation of Loss Firms in a Knowledge-based Economy. Review of Accounting Studies, 12, 61-93. http://dx.doi.org/10.1007/s11142-006-9022-z

Dechow, P. (1994). Accounting Earnings and Cash Flows as Measures of Firm Performance: The Role of Accounting Accruals. Journal of Accounting and Economics, 18, 3-42. http://dx.doi.org/10.1016/0165-4101(94)90016-7

Franzen, L., \& Radhakrishnan, S. (2006). The Value-relevance of Earnings and Book Value across Profit and Loss Firms: The Case of R\&D Spending. working papers.

Gang, W., Dan, L. (2008). The controlling shareholder, type and value of the company. The Stock Market, 8.

George, K. (2008). A thesis submitted for the degree of Masters of Philosophy. School of Social Sciences, Brunel University.

Hayn, C. (1995). The Information Content of Losses. Journal of Accounting and Economics, 20, 125-153. http://dx.doi.org/10.1016/0165-4101(95)00397-2

Jayati, S., \& Subrata, S. (2000). Large shareholder activism in developing countries: Evidence from. India. International Review of Finance, 1, 161-194. http://dx.doi.org/10.1111/1468-2443.00010

Jiang, W., \& Stark, A. (2009). Determinants and Predictions of Loss Reversals in the UK. Manchester Business School. Working Paper.

Jiang, W., Stark, A. (2006). Factors Affecting the Valuation of Loss-Relative to Profit-Making Firms in the UK. working papers.

Jianqiao, L. (1999). China losses of earnings management of market companies empirical research. Accounting Research, 9.

Klein, A., \& Marquardt, C. A. (2006). Fundamentals of accounting losses. The Accounting Review, 81, 179-206. http://dx.doi.org/10.2308/accr.2006.81.1.179

La Porta, R., Lopez-de-Silanes, F., \& Shleifer, A. (1999). Corporate ownership around the world. Journal of Finance, 54, 471-517. http://dx.doi.org/10.1111/0022-1082.00115

Liping, X., Yu, X., \& Gongmeng, C. (2006). The nature of the controlling shareholders and the company business performance. The World Economy, 10. 
Mingxiu, Z. (2005). The first big shareholders nature, research on ownership structure and corporate governance efficiency. Statistics and Decision, 12.

Mishkin, F. (1983). A Rational Expectations Approach to Macro econometrics: Testing Policy Effectiveness and Efficient Markets Models. Chicago, IL, University of Chicago Press for the National Bureau of Economic Research. http://dx.doi.org/10.7208/chicago/9780226531922.001.0001

Peter, J., \& George, A. P. (2005). Valuing Loss Firms. The Accounting Review, 80, 847-870. http://dx.doi.org/10.2308/accr.2005.80.3.847

Riyanto, Y. E., \& Linda, A. T. (2004). Tunneling and propping: a justification for pyramidal ownership. Working Paper.

Shleifer, A., \& Vishny, R. W. (1997). A survey of corporate governance. Journal of Finance, 52, 737-783. http://dx.doi.org/10.1111/j.1540-6261.1997.tb04820.x

Shuang, X. (2010). The economic cycle and the pricing of loss-making companies-theory and empirical research. The Publishing House of Shanghai University.

Xin, Z., \& Dayuan, H. (2008). The loss of market companies will be smooth in the fourth quarter profit? Chinese Accounting Review, 3.

Ying, D., \& Liguo, L. (2002). The equity structure and corporate governance efficiency: an empirical analysis of listed companies in China. Management of the World, 11.

Zengquan, L., Qian, Y., \& Xiaokun, W. (2005). Empty, support and merger, acquisition and reorganization. Economic Research, 1.

\section{Notes}

Note 1 . The loss reversibility refers to the reversal degree in the first quarter after the listed companies suffer loss.

Note 2. Lin Jianxiu (2007) use the control patterns to reflect the first big shareholders at the shareholders' level and board's level in terms of their control, namely whether the first big shareholders at the shareholders' level control and whether at board's level control, it is divided into four different kinds of control mode:controlling both the shareholders and the board (high equity control); neither having control of the shareholders nor the board (low stock control); having the control of the shareholders but no control of the board (high stakes but low control); having no control of the shareholders but control of the board (low equity but high control). If according to this four modes, in the paper here the first big shareholders only refers to the "low equity control" mode, and the other three patterns belong to the modes of shareholders controlling.

\section{Copyrights}

Copyright for this article is retained by the author(s), with first publication rights granted to the journal.

This is an open-access article distributed under the terms and conditions of the Creative Commons Attribution license (http://creativecommons.org/licenses/by/3.0/). 